\title{
Environmental screening of novel technologies to increase material circularity: A case study on aluminium cans
}

Stotz, Philippe Maurice; Niero, Monia; Bey, Niki; Paraskevas, Dimos

Published in:

Resources, Conservation and Recycling

Link to article, DOI:

10.1016/j.resconrec.2017.07.013

Publication date:

2017

Document Version

Peer reviewed version

Link back to DTU Orbit

Citation (APA):

Stotz, P. M., Niero, M., Bey, N., \& Paraskevas, D. (2017). Environmental screening of novel technologies to increase material circularity: A case study on aluminium cans. Resources, Conservation and Recycling, 127, 96106. https://doi.org/10.1016/j.resconrec.2017.07.013

\section{General rights}

Copyright and moral rights for the publications made accessible in the public portal are retained by the authors and/or other copyright owners and it is a condition of accessing publications that users recognise and abide by the legal requirements associated with these rights.

- Users may download and print one copy of any publication from the public portal for the purpose of private study or research.

- You may not further distribute the material or use it for any profit-making activity or commercial gain

- You may freely distribute the URL identifying the publication in the public portal 


\section{Environmental screening of novel}

2 technologies to increase material

3 circularity: a case study on aluminium

4 cans

5

6 Philippe Maurice Stotz ${ }^{a *}$, Monia Niero ${ }^{a}$, Niki Bey ${ }^{a}$, Dimos Paraskevas ${ }^{b}$

7 
P. M. Stotz, M. Niero, N. Bey, and D. Paraskevas

Resour. Conserv. Recycl., vol. 127, no. December, pp. 96-106, 2017

http://dx.doi.org/10.1016/j.resconrec.2017.07.013

15 Abstract

16 It is undisputed that the recycling of aluminium is desirable as long as the environmental and economic implications of its reintegration do not exceed the burdens of its primary production. The efficiency of any aluminium recycling system can be expressed by the total material losses throughout the entire process chain, ideally reaching $0 \%$, thus equivalent to $100 \%$ metal recovery. However, in most cases metals are recycled in open /cascade recycling loop where dilution and quality losses occur. Innovations in $A B C$ design as well as in sorting and recycling technologies have the potential to increase recyclability and avoid downcycling issues due to mixed alloy scrap streams. By means of Life Cycle Assessment (LCA) seven scenarios, comprising specific systemic changes, are compared to the current recycling practice of the used beverage can in the UK. The End-of-Life modelling of recycling is performed in accordance with the equal share method to account for impacts both on the recyclability and the recycled content. The results confirm the primary aluminium production and energy consumption in the $A B C$ production as the hotspots in the life cycle of the $A B C$. The toxicity and energy-related impact categories show the highest susceptibility to increasing recycled content and recycling rate, while the technological novelties show little effect. In terms of abiotic resource depletion the introduction of novel technologies could have the potential to retain quality of the aluminium alloys by either establishing dedicated waste streams or upgrading the aluminium scrap by dedicated sorting strategies.

\section{Keywords:}

33 Aluminium beverage can, Life Cycle Assessment, Recycling, Solid state recycling, Laser induced breakdown spectroscopy, Abiotic resource depletion 
P. M. Stotz, M. Niero, N. Bey, and D. Paraskevas

Resour. Conserv. Recycl., vol. 127, no. December, pp. 96-106, 2017

http://dx.doi.org/10.1016/j.resconrec.2017.07.013

\section{Introduction}

Aluminium has diffused modern times like no other metal next to steel, and its production continues to grow with an average of $3.7 \%$ annually since 40 years (Bauxite Index, 2017). Its physical properties make it an ideal candidate for a large range of industries, from packaging to aerospace, from building and construction to automotive, among many others (EEA, 2017a). Both the primary and secondary production of aluminium is not uncritical. The former is associated with high energy consumption, resource depletion, and high material losses in the different life cycle stages (material production, semi-fabrication and part manufacturing process), as well as the generation of large volumes of bauxite residue (red mud). The latter faces issues with quality losses (when the purity-aluminium content of the produced material is lower than the input material, e.g. by the addition of alloying elements during re-melting) and dilution losses (addition of primary aluminium during re-melting to 'dilute' the concentration of the residual elements that cannot be refined during re-melting) due to a combination of: i) the uncontrolled mixing of scrap streams, ii) accumulation of impurities/tramp elements, and iii) limited melt purification options during re-melting (Paraskevas et al., 2015a). Further, secondary aluminium production is also affected by the high variety in the regional recycling rates (UNEP, 2011), negative social impacts depending on the geographical context (UNEP, 2013), and a potential scrap surplus once the current in-use stock becomes available for recycling (Modaresi and Müller, 2012). Several studies (e.g. Paraskevas et al., 2015b) highlight the fact that recycling of aluminium requires no more than $5 \%$ of the energy compared to primary production, hence presents a real opportunity to reduce environmental impacts, if managed in a sustainable way.

The circularity of any aluminium recycling system can be expressed by the total material losses throughout the entire process chain, ideally reaching $0 \%$, thus equivalent to $100 \%$ material efficiency. Material circularity, as used in the context of this study, refers to a closed material loop, i.e. recycling of the material into the same product, e.g. re-melting of used beverage cans (UBC) to produce new aluminium beverage cans $(A B C)$. Various factors contribute to material circularity in a recycling system (adapted from Hagelüken, 2007). First, it depends on technical factors that determine the process capability (e.g. recovery of specific alloy series) and installed capacity for material recovery. Second, societal and legislative factors motivate or oblige stakeholders to provide the necessary infrastructure or initiate public campaigns to stimulate a 'recycling culture' (i.e. consumer awareness and behaviour). Finally, economic factors play a vital role by creating the incentive for recycling at the consumer level (e.g. deposit schemes) or scrap values (e.g. informal recycling sector). Even though the ultimate target may be a closed material loop, it should be acknowledged that in reality a fully closed material loop is likely to be impossible to achieve. According to UNEP $(2013$, p.93) "There will always be a slight loss of metals due to imperfections in the systems and many other aspects, such as thermodynamics, technology, human error, politics, theft and economics." 
Its physical characteristics make aluminium an ideal material for a range of packaging solutions. As a result, packaging industry absorbs nearly $17 \%$ of the aluminium output, ranking third behind the construction and transportation industries in Europe (EAA, 2017b). The $A B C$ is one of the most widespread form of packaging in Europe, with an output exceeding 64 billion ABCs in 2015, to which the market within the United Kingdom of Great Britain and Northern Ireland (UK) contributes with an annual production of almost 10 billion $A B C s$ (BCME, 2016).

Life Cycle Assessment (LCA) is a scientific methodology that has been successfully applied to quantify the potential environmental impacts of beverage packaging in general (van der Harst et al., 2016; Saleh, 2016; Simon et al., 2015), and the ABC in specific (Stichling and Nguyen-Ngoc, 2009; Niero et al., 2016; Niero and Olsen, 2016). Niero et al. (2016) have conducted a scenario-based LCA on the ABC in the UK market with varying recycled content and renewable energy consumption. Niero and Olsen (2016) performed a simulation of a closed loop scenario with reintegration of different sources and amounts of packaging scrap (mixed packaging scrap and UBC) in order to determine the effect on the alloying components. Main conclusion of the latter study was that the incorporation of alloying elements/composition of the metal streams into the LCA has a significant effect on the impact results and should consequently be considered (Paraskevas et al., 2013).

The present study investigates the potential increase of material circularity by employing novel sorting and recycling technologies. It considers mainly the conditions in Europe and focuses in particular on the UK, where the introduction of such novel technologies could lead to a substantial improvement of the purity of the waste stream.

\subsection{Aluminium Beverage Cans in the UK context}

The standard $A B C$ is composed of a body (i.e. the container) and an end, in which the opening is punched and the tab riveted. The coil manufacturer supplies the respective aluminium sheets for the body (AA3004) and the end (AA5182). Production scrap is routed back to the coil supplier for recycling, hence is already managed in a closed loop (Stichling and Nguyen-Ngoc, 2009). Body and end are subsequently transported to the beverage producer, who fills and seams the $A B C$, and sells the product to the consumer through a distribution network of wholesalers and retailers.

Two individual collection schemes for used beverage cans (UBC) are implemented in the UK (Seyring et al., 2016). While any household may dispose of its UBC with a co-mingled waste stream (joint collection of plastic, metal and glass packaging), Every Can Counts, a UK-based partnership between drink can manufacturers and the recycling industry, has introduced bring-point solutions for a variety of organisations at which the UBC is collected separately (http://www.everycancounts.co.uk/). Mixed 
P. M. Stotz, M. Niero, N. Bey, and D. Paraskevas

Resour. Conserv. Recycl., vol. 127, no. December, pp. 96-106, 2017

http://dx.doi.org/10.1016/j.resconrec.2017.07.013

100

101

102

103

104

105

106

107

108

109

110

111

112

113

114

115

116

117

118

119

120

121

122

123

124

125

126

127

128

129

130

131

132

packaging scrap from households undergoes a sequence of sorting steps separating glass and plastic from the metal fraction, which is further sorted into ferrous and non-ferrous metals. The non-ferrous fraction is subject to additional sorting to separate heavy metals from aluminium (ALFED, 2017). The aluminium scrap at this point contains a mix of cast and wrought aluminium alloys, with high and low compositional tolerances in alloying element concentration respectively. This mixed alloy steam is mostly absorbed in the cast alloy production, which results in downcycling of the wrought scrap fraction to cast alloy. This form of recycling is commonly described in literature as "cascade recycling" or "downrecycling" or "open loop recycling", as there is an accumulation of residual/alloying elements to lower purity alloy systems. Dilution losses on the other hand, occur when primary aluminium is added to reduce the concentration of residual elements in the scrap stream. Both dilution and quality losses during re-melting results in primary resource depletion (primary aluminium and alloying elements addition) and can be minimised by optimal material clustering prior re-melting (Paraskevas et al., 2015a).

\subsection{Technological innovations in aluminium recycling}

A wealth of research is dedicated to the improvement of aluminium recycling routes, and is primarily focussed on the pyrometallurgical re-melting route. Three main objectives can be derived from the stateof-the-art in recycling technologies: i) retention of the purity of the metal streams, ii) reduction of material losses in pre-processing (e.g. collection and sorting) and re-melting and further processing, iii) reduction in energy consumption in primary and secondary production. Main research topics are dross recycling (Bellqvist et al., 2015; Ingason and Sigfusson, 2014), refining/removal of specific alloying elements (Nakajima et al., 2011, 2012; Gesing et al., 2015), or sorting technologies and strategies (Gaustad et al., 2012; Nogueira et al., 2015; Takezawa et al., 2014). However, the reduction of material losses and energy consumption by incremental improvements seem to have reached a plateau after which only marginal savings are conceivable, hence opening the field for alternative technologies.

Two notable approaches promised to deliver great benefit, not only in decreasing material and quality losses, but also a reduction of greenhouse gas emissions. Laser induced breakdown spectroscopy (LIBS) is a sorting technology which has had its market introduction at Düsseldorf's Aluminium Trade Fair in 2016 and has the capability to sort specific wrought alloys (Steinert, 2016; Hegazy et al., 2013; Takezawa et al., 2014). Several companies have developed prototypes that prove the concept with reliable and repeatable results. The LIBS technology can be applied as extension of the current sorting infrastructure to produce alloyspecific scrap streams, hence providing the re-melter with a high-quality feedstock that minimizes the input of alloying elements and primary aluminium to dilute impurities (see Gaustad et al., 2012 for a discussion on sorting technologies). Solid state recycling (SSR) has been in research since 1945 (Stern, 1945), but has recently attracted increased attention as various methods and studies have proven its potential to 
P. M. Stotz, M. Niero, N. Bey, and D. Paraskevas

Resour. Conserv. Recycl., vol. 127, no. December, pp. 96-106, 2017

http://dx.doi.org/10.1016/j.resconrec.2017.07.013

133 complement the traditional re-melting route by solid state scrap processing of light metal scrap (Paraskevas

134 et al., 2014; Paraskevas et al., 2016; Behrens et al., 2016; Shamsudin et al., 2016). Current SSR prototypes

135 are able to process 'new' or production scrap into near net semi-products and profiles by hot processing

136 aluminium scrap below melting point in addition to exposure to severe plastic deformation (e.g. via hot

137 extrusion) and/or by diffusion bonding (e.g. via Spark Plasma Sintering) (Paraskevas et al., 2014; Paraskevas

138 et al., 2016). While all studies use machining chips, a relatively clean and high quality feedstock, for the

139 recycling step, it has to be seen to which extent the technology is able to deal with varying scrap size and

140 impurities. The major benefit of SSR is the avoidance of unrecoverable material losses due to oxidation

141 during remelting (approx. 5\% and at the levels of 15\% for fine form scrap) (Duflou et al., 2015). However

142 SSR does not offer the possibility to readjust the alloy composition (i.e. scrap input equals output alloy) and

143 consequently requires well defined or single alloy stream. None of the SSR technologies has been

144 introduced to market today (Paraskevas et al, 2013).

$145 \quad 1.3 \quad$ Aim of the study

146 This study provides insights on the environmental performance of novel technologies to increase material 147 circularity in the $A B C$ recycling industry. The UK market is chosen for a case study in order to perform a 148 comparative LCA of eight scenarios including different sorting and recycling technologies, configurations of 149 the can, and waste management options. The LCA concludes in a hotspot assessment of each scenario and 150 defines the respective environmental impact abatement potential in comparison to the current practice.

151 The study addresses challenges associated with the assessment of novel technologies and engages in the 152 on-going debate on methodological choices in LCA such as End-of-Life (EoL) modelling and selection of life 153 cycle impact assessment (LCIA) methods.

154 


\section{Methodology}

156

157

158

159

160

161

162

163

164

165

166

167

168

169

170

171

172

173

174

175

176

177

178

179

\subsection{Scenario development}

A total of eight scenarios have been formulated for the comparative LCA. The first is considered as the baseline scenario (S1), describing the current $A B C$ system in the UK in accordance with section 1.1. Its main characteristics are the co-mingled metal waste stream, subject to sorting prior to re-melting into cast alloy ingots, i.e. lower purity output. Scenario two (S2) introduces a uni-alloy can in the base scenario. As opposed to the standard dual-alloy ABC, it is produced out of the AA3004 sheet entirely. This type of can has been object of research (e.g. Novelis, 2012), but has never been introduced to the market. The uni-alloy can in itself is not interesting as a scenario due to its higher weight (and therefore resource consumption), but may benefit a closed material loop in combination with the other here considered technologies. Hence, scenario three (S3) combines SSR with the uni-alloy can, as the SSR route is only capable of handling one specific alloy at once, rendering it infeasible with the standard dual-alloy $A B C$. Diffusion bonding is chosen as the specific SSR technology, under the inclusion of the entire sintering cycle, assuming that the scrap preparation remains similar to the re-melting route. Scenario four and five introduce LIBS as an extension to the existing sorting infrastructure, once with the standard $\mathrm{ABC}$ (S4) and once with the uni-alloy type (S5). Scenario six and seven consider the introduction of a return system, as for example implemented in the Danish market. The return system is considered a closed material loop, as the UBC is directly sold to the coil manufacturer and is therefore reintegrated in the $A B C$ system. The two scenarios simply differ in the applied recycling rates, which correspond to the ones reported by both countries in 2015, i.e. UK (S6) (Stanford, 2016) and DK (S7) (Dansk retursystem, 2016), respectively. Scenario eight (S8) represents an 'ideal system' in terms of recycling rate and recycled content of the input material. Both are considered to reach $100 \%$, however material losses due to sorting and re-melting remain constant (approx. $10 \%$ cumulative for all scenarios except S3, see 2.2.2). Table 1 summarizes the main characteristics of each tested scenario.

Table 1 - Aluminium beverage can $(A B C)$ scenario overview.

\begin{tabular}{|l|l|}
\hline ID & Description \\
\hline S1 & Base scenario - Current practice in UK \\
\hline S2 & Base scenario but with uni-alloy can \\
\hline S3 & Solid state recycling \& uni-alloy can \\
\hline S4 & Sorting by Laser Induced Breakdown Spectroscopy (LIBS) \\
\hline S5 & Uni-alloy can \& sorting by Laser Induced Breakdown Spectroscopy (LIBS) \\
\hline
\end{tabular}


P. M. Stotz, M. Niero, N. Bey, and D. Paraskevas

Resour. Conserv. Recycl., vol. 127, no. December, pp. 96-106, 2017

http://dx.doi.org/10.1016/j.resconrec.2017.07.013

\begin{tabular}{|l|l|}
\hline S6 & Return system - closed material loop as current practice in DK, with UK recycling rate of 69\% (2015) \\
\hline S7 & Return system - closed material loop as current practice in DK, with DK recycling rate of $90 \%$ (2015) \\
\hline S8 & 'Ideal system' - closed material loop with $100 \%$ recycling rate and $100 \%$ recycled content \\
\hline
\end{tabular}

180

181

182

183

184

185

186

187

188

189

190

191

192

193

194

195

196

197

198

199

200

201

202

203

204

205

206

207

208

\subsection{Life Cycle Assessment}

The LCA study was conducted in adherence with the ISO 14040-44 standards (ISO, 2006a, 2006b) and ILCD Handbook requirements (EC-JRC-IES, 2011). The following sections present: the goal and scope definition (section 2.2.1), life cycle inventory (LCI) (section 2.2.2), life cycle impact assessment (LCIA) (section 2.2.3) and sensitivity analyses (section 2.2.4), as part of the life cycle interpretation. Scenario modelling is one of most used methods to estimate uncertainty propagation in LCA (Lyod and Ries, 2007) and has been considered in the present study.

\subsubsection{Goal \& scope definition}

The goal of this comparative study is twofold: i) to provide an initial screening of the hotspots in the ABCs life cycle and ii) to establish the environmental impact abatement potential of each scenario in order to enable strategic decisions towards increased material circularity.

For the purpose of this study the functional unit (FU) has been defined as: "the production of 1000 pieces of $50 \mathrm{cl} A B C s^{\prime \prime}$. The FU reflects the focus on the can and is in line with other studies of similar scope, e.g. Stichling and Nguyen-Ngoc (2009). The 50cl size was selected due to data availability from a project partner and based on the argument that the size is secondary when performing an analysis on the materials' circularity i.e. no comparison to other sizes or container types.

A number of methods have emerged to model the recycling of materials in LCA, all of which emphasizing different stage in the life cycle, but little guidance is given in terms of standardisation (see van der Harst et al., 2016). Depending on the choice of method, credit is given to the recycled content, the recycling (avoided production) or a mix of both, its burdens and credits distributed respectively. The equal share method (ES) was chosen as the standard modelling approach, while the method substitution with equal quality (SEQ) has been introduced as part of the sensitivity analysis (section 2.2.4). ES distributes credits and burdens associated with resource consumption and EoL in equal shares. It therefore rewards both the increase in recycled content, as well as a high recyclability and is the recommended method in the Product Environmental Footprints (PEF) guide (EC, 2013). This approach is recommended for use in the context of policy support applications (Allacker et al., 2014) and has been used in recent LCAs on aluminium cans (e.g. van der Harst et al. 2016, Niero and Olsen 2016). As opposed to ES, SEQ assumes that the production of a product is based on $100 \%$ virgin materials, regardless whether secondary aluminium might be used in 
reality, and gives full credit to any recycled material in the EoL stage. The latter has been included based on its recommendation by the metals industry (Santero and Hendry, 2016) and the European Aluminium Association (EAA, 2013). Figure 1 illustrates the system boundaries of the $A B C$ system considered in the study in accordance with the ES method. Upstream of the excluded distribution and use of the $A B C$, shared processes include the recycling of the scrap arising from the production of the $A B C$ body and end, in addition to the recycled content fraction. Subsequent to the disposal of the UBC by the consumer, the nonrecycled share is either landfilled or incinerated. The respective burdens and credits (heat and electricity recovery) are fully attributed to the current life cycle, whereas the burdens and credits arising from the recycling of the UBC are distributed in equal shares (50/50).

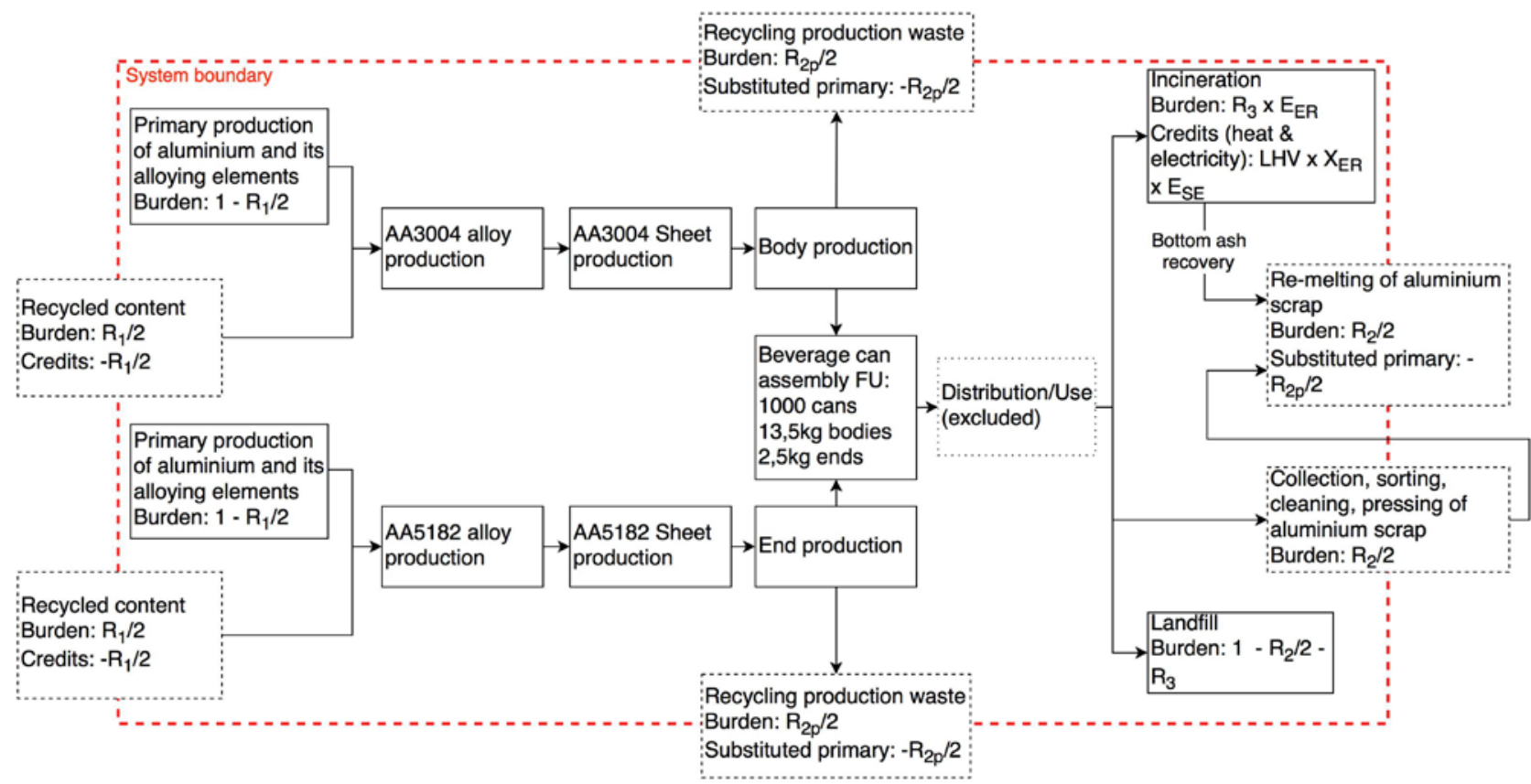

Figure 1 - System boundaries as modelled with the equal share method. The transport of the empty $A B C / U B C$ is included, while the distribution and use of the filled $A B C$ are excluded. The burdens and credits are calculated in accordance with the Product Environmental Footprint (PEF) baseline formula (EC, 2013). $\mathbf{R}_{1}$ : Recycled content; $\mathbf{R}_{2}$ : Recycling rate; $R_{2 p}$ : Recycling rate production scrap; $R_{3}$ : Incinerated fraction; LHV: Lower Heating Value; $X_{E R}$ : Efficiency of Energy recovery; $E_{S E}$ : Avoided emissions and resource consumption of substituted energy source.

\subsubsection{Life cycle inventory}

227 To compile a complete inventory, a number of assumptions were made based various sources. While some 
229 reflect systemic changes arising from the implementation of a given technological innovation or collection

230 system (upper part of Table 2).

Table 2 - Scenario Assumptions, including assumptions valid for all the scenarios (in italic, lower part) and specific scenario-assumptions (upper part).

\begin{tabular}{|c|c|c|c|c|c|c|c|c|c|}
\hline Assumptions & Source & S1 & S2 & S3 & S4 & S5 & S6 & $\begin{array}{l}5 \\
7\end{array}$ & S8 \\
\hline Average recycled content $(\mathrm{RC})=50 \%$ & EAA, 2013 & $\mathrm{X}$ & $\mathrm{X}$ & $\mathrm{X}$ & $\mathrm{X}$ & $\mathrm{X}$ & $x$ & $\mathrm{X}$ & \\
\hline UK's recycling rate in $2015=69 \%$ & Stanford, 2016 & $\mathrm{X}$ & $\mathrm{X}$ & $\mathrm{X}$ & $X$ & $X$ & $\mathrm{X}$ & & \\
\hline DK's recycling rate in $2015=90 \%$ & $\begin{array}{l}\text { Dansk retursystem, } \\
2016\end{array}$ & & & & & & & $\mathrm{X}$ & \\
\hline Weight of end (5182 alloy) $=2,5 \mathrm{~g}$ & - & $\mathrm{X}$ & & & $\mathrm{X}$ & & $\mathrm{X}$ & $\mathrm{X}$ & $\mathrm{X}$ \\
\hline $\begin{array}{l}\text { Weight of end ( } 3004 \text { alloy) }=3 g \text { (assumed weight } \\
\text { increase of } 20 \%)\end{array}$ & - & & $\mathrm{X}$ & $\mathrm{X}$ & & $\mathrm{X}$ & & & \\
\hline Average material losses during remelting $=5 \%$ & Duflou et al., 2015 & $\mathrm{x}$ & $\mathrm{X}$ & & $\mathrm{X}$ & $x$ & $x$ & $\mathrm{x}$ & $\mathrm{X}$ \\
\hline Weight of Body (3004 alloy) $=13 \mathrm{~g}$ & - & $x$ & $x$ & $x$ & $x$ & $x$ & $x$ & $x$ & $x$ \\
\hline $\begin{array}{l}\text { EoL treatment of the non-recycled fraction: landfill } \\
\text { (88.8\%) and incineration (11.2\%) }\end{array}$ & DEFRA, 2016 p.11 & $x$ & $x$ & $\mathrm{X}$ & $\mathrm{X}$ & $x$ & $x$ & $x$ & $\mathrm{x}$ \\
\hline $\begin{array}{l}\text { Production scrap (equal to } 15 \% \text { of the aluminium } \\
\text { coil) is recycled in a closed loop }\end{array}$ & $\begin{array}{l}\text { Stichling and Nguyen- } \\
\text { Ngoc, } 2009\end{array}$ & $\mathrm{X}$ & $\mathrm{X}$ & $\mathrm{x}$ & $\mathrm{X}$ & $x$ & $x$ & $\mathrm{x}$ & $\mathrm{X}$ \\
\hline $\begin{array}{l}\text { Material losses throughout scrap collection, sorting } \\
\text { and preparation }=5 \%\end{array}$ & Paraskevas et al., $2015 a$ & $x$ & $x$ & $x$ & $\mathrm{X}$ & $\mathrm{X}$ & $x$ & $\mathrm{x}$ & $x$ \\
\hline $\begin{array}{l}30 \% \text { recovery rate of aluminium fraction from } \\
\text { bottom ash }\end{array}$ & Wernet et al., 2016 & $x$ & $x$ & $x$ & $x$ & $x$ & $x$ & $x$ & $x$ \\
\hline
\end{tabular}

234 The LCA was performed considering the standard aluminium alloy composition, as suggested by Niero and

235 Olsen (2016). The aluminium alloys were modelled with an average in-between the minimal and maximal 236 tolerance regarding each alloying element (Table 3). UBC scrap has been used as a feedstock to model the 237 recycled content, on which basis the primary elements have been calculated to match the target alloy's 238 composition requirements.

Table 3 - Average composition in terms of mass fraction of alloying elements for the modelled aluminium alloys.

All figures in \%wt. Derived from DIN EN 573-3 (AA3004 \& AA 5182) and EN 13920:2003 (UBC scrap)

\begin{tabular}{|c|c|c|c|c|c|c|c|c|c|}
\hline & $\mathrm{Mg}$ & Mn & $\mathrm{Fe}$ & Si & $\mathrm{Cu}$ & $\mathrm{Zn}$ & $\mathrm{Cr}$ & $\mathrm{Ti}$ & Al \\
\hline AA3004 & 1.05 & 1.25 & 0.7 & 0.3 & 0.25 & 0.25 & - & - & 96.2 \\
\hline AA5182 & 4.5 & 0.35 & 0.35 & 0.2 & 0.15 & 0.25 & 0.1 & 0.1 & 94 \\
\hline
\end{tabular}


P. M. Stotz, M. Niero, N. Bey, and D. Paraskevas

Resour. Conserv. Recycl., vol. 127, no. December, pp. 96-106, 2017

http://dx.doi.org/10.1016/j.resconrec.2017.07.013

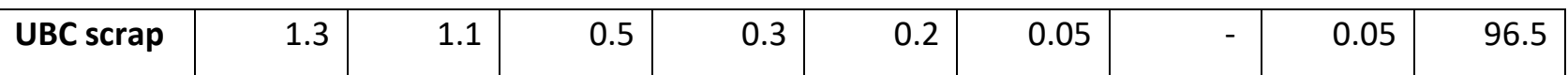

242 The key figures regarding electricity consumption in the $A B C$ production have been derived from two

243 sources, of which both refer to primary data collection. Stichling and Nguyen-Ngoc (2009) reported the

244 electricity consumption for the body and the end at $417.89 \mathrm{MJ} / \mathrm{FU}$ and $13.48 \mathrm{MJ} /$ FU respectively. Niero and

245 Olsen (2016) reported a 12.64MJ/FU for the filling and seaming processes. The electric power consumption

246 is assumed to be similar for both types of ABC, i.e. uni-alloy and dual-alloy and is modelled as a high voltage

247 market mix in the UK as documented in the ecoinvent datasets (45\% hard coal, 15\% natural gas, $18 \%$

248 nuclear, 14\% combined heat and power, 8\% wind; Wernet et al., 2016).

249 Transport intensity is subject to great variation throughout the entire ABC life cycle, depending on the 250 locations of the individual processing factories. Hence, averaged distances, derived from van der Harst et al. 251 (2016) and Niero et al. (2016) have been applied for the modelling (Table 4). The production scrap of both 252 body and end are typically collected by the sheet producer and returned by the same means and modelled 253 accordingly. Upstream transportation within primary resource production up until sheet rolling in addition 254 to the EoL-transportation are adapted from the ecoinvent datasets (Wernet et al., 2016).

Table 4 - Distance in-between the various production stages as reported and modelled.

\begin{tabular}{|c|c|c|c|}
\hline Origin & Destination & Distance (km) & Mode of Transport \\
\hline Sheet production & Can manufacturer & 400 & \multirow{3}{*}{$\begin{array}{l}\text { Transport, lorry } 16-32 \\
\text { metric ton, EURO4 }\end{array}$} \\
\hline Can manufacturer & Beverage producer & 29 & \\
\hline Beverage producer & Warehouse & 100 & \\
\hline
\end{tabular}

257 The modelling of the life cycle was performed in Simapro 8.2.3.0 (Goedkoop et al., 2016), using the 258 ecoinvent v3.1 database (Wernet et. al., 2016)

\section{$259 \quad$ 2.2.3 Life cycle impact assessment}

260 The study follows the recommendations of Santero and Hendry (2016), who discussed the harmonization of 261 LCA methodologies for the metal and mining industry. The impact categories are thus: global warming 262 potential (GWP), acidification potential, eutrophication potential, smog potential, and ozone depletion 263 potential (Santero and Hendry, 2016). Based on the recommendations of the European Commission's Joint 264 Research Centre (Hauschild et al., 2013), the ILCD 2011 Midpoint+ V1.08 impact assessment method (EC265 JRC-IES, 2012) was chosen as a reference. Therefore, the following ILCD recommended impact categories 266 have been considered: climate change, ozone depletion, particulate matter, acidification, terrestrial, 267 marine and freshwater eutrophication. In addition, the toxicity related impact categories human toxicity 
P. M. Stotz, M. Niero, N. Bey, and D. Paraskevas Resour. Conserv. Recycl., vol. 127, no. December, pp. 96-106, 2017 http://dx.doi.org/10.1016/j.resconrec.2017.07.013

cancer and non-cancer, and freshwater ecotoxicity are included and assessed with the USEtox impact assessment method (Rosenbaum al., 2008; ILCD recommended). Further, the impact category abiotic resource depletion is included, although "there is no scientifically correct method to derive characterization factors" (Oers and Guinée, 2016, p.1). Drielsma et al. (2016a) argue that resource availability rather depends on markets, politics and technology, than a theoretical environmental constraint and attest LCA an inadequate performance in quantifying those dependencies. As a consequence, LCA studies with the potential to improve the current datasets in resource depletion, omit the inclusion of abiotic depletion altogether (Van Genderen et al., 2016) or even advise against its use (Santero and Hendry, 2016). However, in order to conform with the goal of this study to provide an initial screening, while still producing results that allow conclusions on material circularity, it was decided to include an additional three commonly applied methods for AD characterization. The CML baseline method (version 3.03; van Oers et al., 2002), an enhanced method compared to the ILCD recommended CML non-baseline method (version 3.02; Guinée et al., 2002), has been chosen as it differentiates between $A D$ 'elements' and AD 'fossil fuels' (Oers and Guinée, 2016). Further, Impact 2002+ version 2.12 (Jolliet et al. 2003), based on the damage characterisation factors of the Eco-Indicator99 method as developed by Goedkoop and Spriensma (2001) and Recipe Midpoint version 1.08 (Goedkoop et al. 2013) have been applied.

Novel, more robust, impact assessment methods are under development. Schneider et al. (2015) reported characterisation factors for AD (anthropogenic stock extended abiotic depletion (AADP)), which have been included as a fifth and final impact assessment method.

Table 5 - Overview of recommend and applied impact categories and assessment methods

\begin{tabular}{|c|c|c|}
\hline Impact categories & Recommended by & Applied impact assessment method \\
\hline $\begin{array}{l}\text { Climate change, ozone } \\
\text { depletion, particulate } \\
\text { matter, acidification, } \\
\text { terrestrial, marine and } \\
\text { freshwater eutrophication }\end{array}$ & $\begin{array}{l}\text { - Santero and Hendry } \\
\text { (2016) } \\
\text { - Hauschild et al., } 2013\end{array}$ & $\begin{array}{l}\text { - ILCD } 2011 \text { Midpoint+ V1.08 (EC-JRC-IES, } \\
\text { 2012) }\end{array}$ \\
\hline $\begin{array}{l}\text { Human toxicity cancer and } \\
\text { non-cancer, freshwater } \\
\text { ecotoxicity }\end{array}$ & - Hauschild et al., 2013 & $\begin{array}{l}\text { - USEtox impact assessment method } \\
\text { (Rosenbaum al., 2008) }\end{array}$ \\
\hline Abiotic resource deletion & $\begin{array}{l}\text { - Hauschild et al. (2013) } \\
\text { (recommend the CML }\end{array}$ & $\begin{array}{l}\text { - CML baseline method (version 3.03; van } \\
\text { Oers et al., 2002) }\end{array}$ \\
\hline
\end{tabular}


P. M. Stotz, M. Niero, N. Bey, and D. Paraskevas Resour. Conserv. Recycl., vol. 127, no. December, pp. 96-106, 2017 http://dx.doi.org/10.1016/j.resconrec.2017.07.013

End-point modelling is deliberately not applied here, since it is considered relevant to establish, whether or not all impact categories follow the same trend (i.e. are sensitive to the same parameters) when comparing across scenarios.

\subsubsection{Sensitivity analyses}

293 The performed LCA included several sensitivity analyses. In terms of EoL modelling, the ABC life cycle has been modelled in accordance with SEQ and ES methods (see 2.2.1). At the LCl level, fluctuations in electricity consumption in production and transport intensity were tested. As the electricity consumption is modelled based on data from 2009, the analysis includes a reduction by $10 \%$. This is assumed to be a realistic reduction based on recent efforts of the aluminium industry to decrease its power consumption in production.

To analyse the results' sensitivity towards transport intensity, the cumulated distances have been increased until they start to affect the results significantly (i.e. 10\% of total GWP impact in base scenario S1, see Humbert et al. (2009) for a discussion on significance). ABC weight, recycling rate and recycled content have not explicitly been included in the sensitivity analyses as they are subject to change within the individual scenarios. Finally, at the LCIA level, the impact on AD has been calculated with the five distinct 
P. M. Stotz, M. Niero, N. Bey, and D. Paraskevas

Resour. Conserv. Recycl., vol. 127, no. December, pp. 96-106, 2017

http://dx.doi.org/10.1016/j.resconrec.2017.07.013

306

307

308

309

310

311

312

313

314

315

316

317

318

\section{Results}

The LCIA results are characterized and normalized at midpoint with the exception of the AD impact category, which is evaluated independently and is consequently not normalized. Weighting and aggregation as optional steps are omitted, as they do not deliver any further information on the circularity of materials.

\subsection{Energy related impact categories}

Similar trends can be observed across all impact categories recommended by Santero and Hendry (2016) (Figure 2). This is consistent with the findings of Laurent et al. (2010), who established a positive correlation in-between those impact categories, provided the primary driver is the energy consumption. In the case of the $A B C$ life cycle, the production of the primary aluminium and the $A B C$ are the main contributors to the GWP, both being energy-intensive processes. Hence hereafter, the discussion focusses on the GWP.

In terms of GWP, all scenarios with $50 \%$ recycled content and $69 \%$ recycling rate show a similar performance across the entire life cycle (S1-6, Figure 3). The variations are with $\pm 3 \%$ pretty narrow and may originate from the uncertainty of modelling, therefore they may be considered insignificant (i.e. below $10 \%)$. In any of these scenarios, the production of primary aluminium and the energy consumption in the $A B C$ production are responsible for the greatest share of GWP with $42 \%$ and $46 \%$ respectively.

Approximately $25 \%$ of the electric energy consumption can be attributed to the filling and seaming process, while the remaining share arises from the $A B C$ body and end production.

Surprisingly, the scenarios with technological changes (S2 - S6) perform consistently worse than the base scenario. In case of S2 and S5, this is primarily due to the increased resource consumption due to the higher weight of the uni-alloy can. The LIBS and return system scenarios (S4 \& S6) on the other hand, perform worse, due to the fact that they account for avoided production of the alloying elements, which have a lower carbon emission in their production compared to primary aluminium (i.e. GWP (100\% aluminium) > GWP (94\% aluminium + 6\% alloying elements)). Overall, the SSR route (S3) shows the highest GWP as the final recycling step is energy intensive (included in remaining processes in Figure 3). Yet, it is important to highlight that the respective data is based on an experimental settings and the process expected to improve in efficiency once scaled up (Duflou et al. 2015). Additionally, S3 results in a slightly decreased aluminium primary production compared to S2 due to the reduced materials losses in the recycling step (from 72.2 to $71.4 \mathrm{~kg} \mathrm{CO}$ eq/FU).

The return system scenario with the UK recycling rate of $69 \%$ (S6) performs similar to the above discussed scenarios, while an increase of the recycling rate to $90 \%$ UBC (S7) shows a reduction of impacts in the range of $8 \%$ of the total GWP. This might be more conservative than in reality, as the model assumes the same $5 \%$ losses for scrap preparation as all other scenarios. Since the return system does not require any sorting 
P. M. Stotz, M. Niero, N. Bey, and D. Paraskevas Resour. Conserv. Recycl., vol. 127, no. December, pp. 96-106, 2017 http://dx.doi.org/10.1016/j.resconrec.2017.07.013

338 prior to re-melting, these losses might actually be less significant. Conversely, the increased transport 339 intensity associated with a return system might lead to an increase in GWP. However, it can be clearly 340 shown that a combined increase of the recycling rate and the recycled content has the highest abatement 341 potential (38\% in S8 Figure 3), leaving the electricity consumption in the ABC production as the major 342 contributor to the impact category.

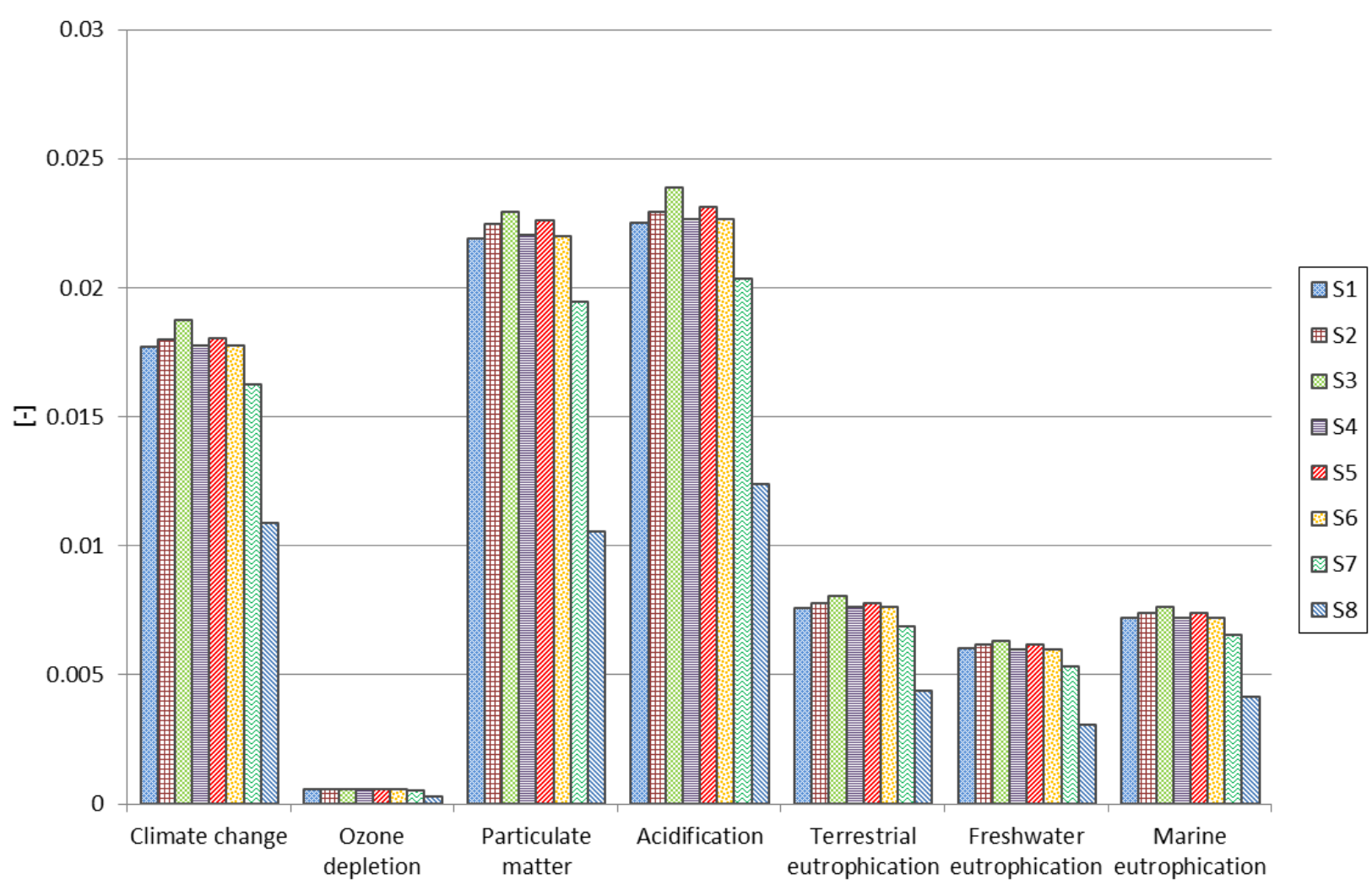

Figure 2 - Normalized impact results of all scenarios (S1-S8). See Table 1 for description of scenarios. 
P. M. Stotz, M. Niero, N. Bey, and D. Paraskevas Resour. Conserv. Recycl., vol. 127, no. December, pp. 96-106, 2017 http://dx.doi.org/10.1016/j.resconrec.2017.07.013

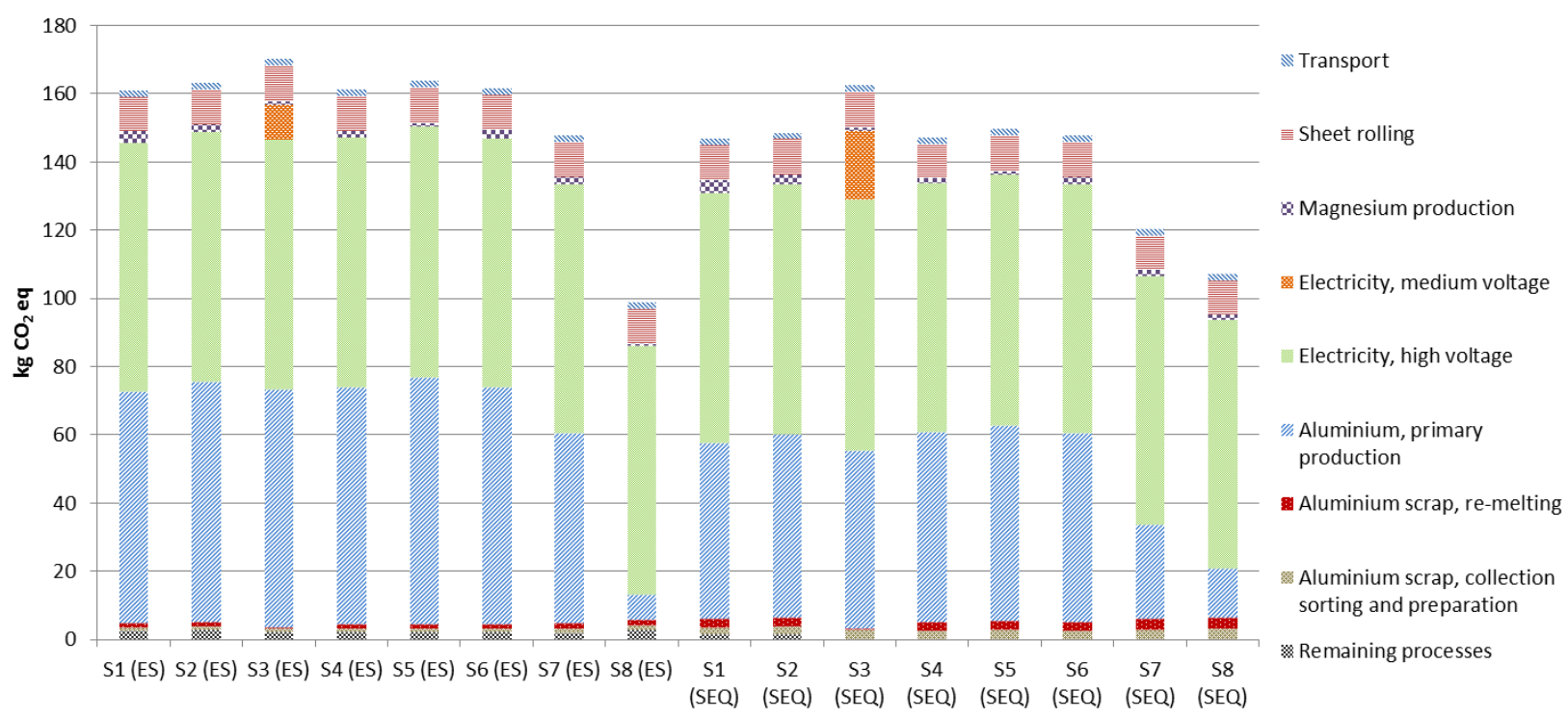

Figure 3 -Global Warming Potential (GWP) results of each scenario and the respective process contribution (1\% cut-off). The scenarios have been modelled with the equal share (ES) and Substitution with equal quality (SEQ) method.

\subsection{Toxicity related impact categories}

352 The toxicity impact categories follow the same trends as observed for the ones driven by energy consumption. The primary aluminium production, respectively the deposition of red mud arising from the process, is the main contributor to the impacts. As a consequence, the impact categories respond well to an increase of the recycled content and recycling rate (Figure 4). Figure 5 illustrates the relative substance contribution in the three impact categories. For human toxicity (cancer) and freshwater ecotoxicity, chromium VI/water shows the highest contribution to the respective impacts. In both cases the emission arises from the primary production of aluminium (72\%) and manganese (24\%). The impact of human toxicity (non-cancer) is driven by arsenic/water and mercury/air emissions, yet again, they originate primarily from the aluminium production and to some extend from the energy production. 
P. M. Stotz, M. Niero, N. Bey, and D. Paraskevas Resour. Conserv. Recycl., vol. 127, no. December, pp. 96-106, 2017 http://dx.doi.org/10.1016/j.resconrec.2017.07.013

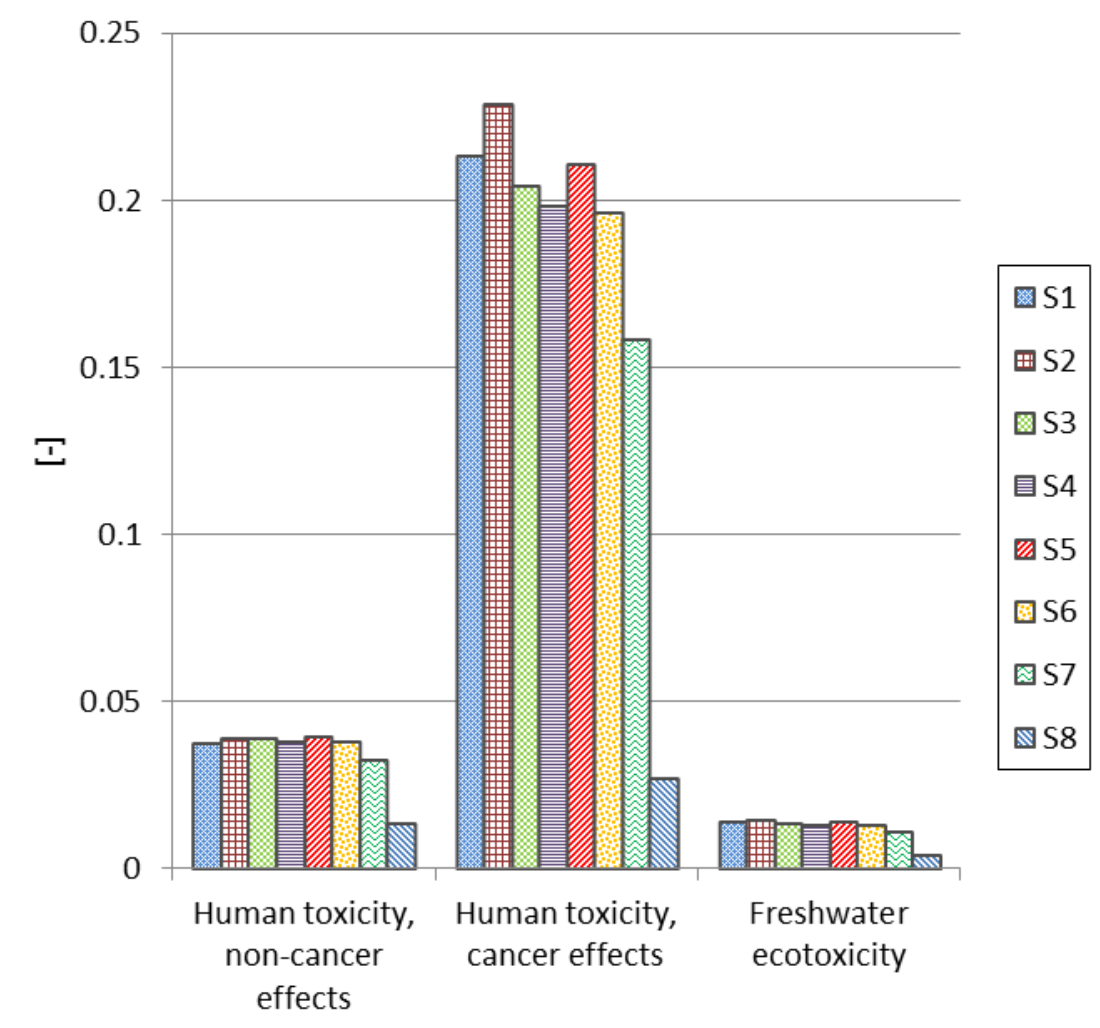

363 Figure 4 - Scenario comparison for toxicity impact categories, i.e. human toxicity (cancer and no-cancer) and 364 freshwater ecotoxicity (Rosenbaum al. 2008). 
P. M. Stotz, M. Niero, N. Bey, and D. Paraskevas

Resour. Conserv. Recycl., vol. 127, no. December, pp. 96-106, 2017 http://dx.doi.org/10.1016/j.resconrec.2017.07.013

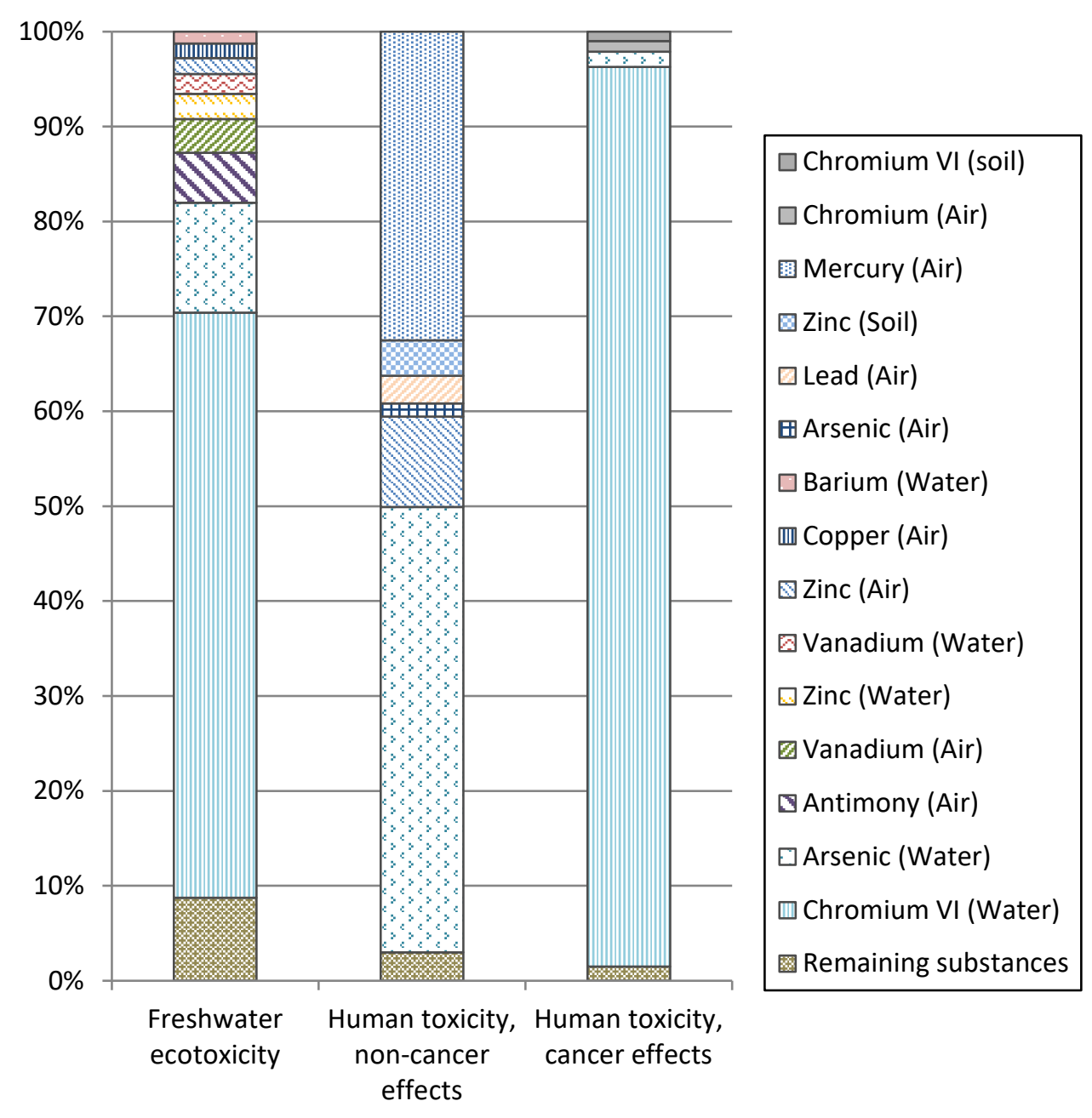

Figure 5 - Relative substance contribution in the toxicity related impact categories. In brackets the final emission compartment is reported.

\subsection{Abiotic resource depletion}

The five impact assessment methods applied for the abiotic depletion revealed inconsistent results in terms of relative substance contributions (Figure 6). The two CML methods (CML non-baseline as applied in ILCD 2011 Midpoint+ and CML baseline) show a high impact due to substance depletion of indium, lead and cadmium - each a by-product of the zinc mining process. Impact $2002+$ assigns $85 \%$ of the impact to the depletion of aluminium resources, whereas in Recipe, the same $85 \%$ are allocated to manganese. AADP assigns $98 \%$ of the impact to cadmium, all other substances remain below the $1 \%$ cut-off criteria.

The differing focus of the methods can as well be illustrated by the abatement potentials of the individual scenarios. While the CML and AADP methods suggest an approximate impact reduction of $20 \%$ (worst (S2)

378 to best (S6); at constant recycled content and recycling rate), Recipe suggests a $48 \%$ and Impact 2002+ merely a $4 \%$ abatement potential. The latter is a consequence of the emphasis on aluminium depletion, 
P. M. Stotz, M. Niero, N. Bey, and D. Paraskevas Resour. Conserv. Recycl., vol. 127, no. December, pp. 96-106, 2017 http://dx.doi.org/10.1016/j.resconrec.2017.07.013

hence no benefit is derived from the recovery of the alloying elements i.e. the method is practically indifferent to the alloy composition of the recycled aluminium output (wrought vs. cast alloy).

However, the observed trend throughout the scenarios remains similar throughout each impact assessment method (Figure 7). The base scenarios with either ABC option (S1 and S2) have the highest potential impact due to the mixed scrap output and the resulting quality losses during re-melting (downcycling). The remaining scenarios with 69\% recycling rate perform similarly, highlighting the benefit of either an aggressive sorting prior to re-melting or a closed product loop alternatively. Further, it can be concluded that both an increased recycled content and recycling rate make the biggest difference on the scenarios (S7 and S8). S7 performs similar to S1-S6 as the recycled content remains constant (50\%) and the recycling rate is only improved by $21 \%$. S 8 however assumes $100 \%$ recycled content and recycling rate, defacto resulting in an increase of $81 \%$ avoided production compared to S1-S6 (+50\%RC \& +31\%RR).

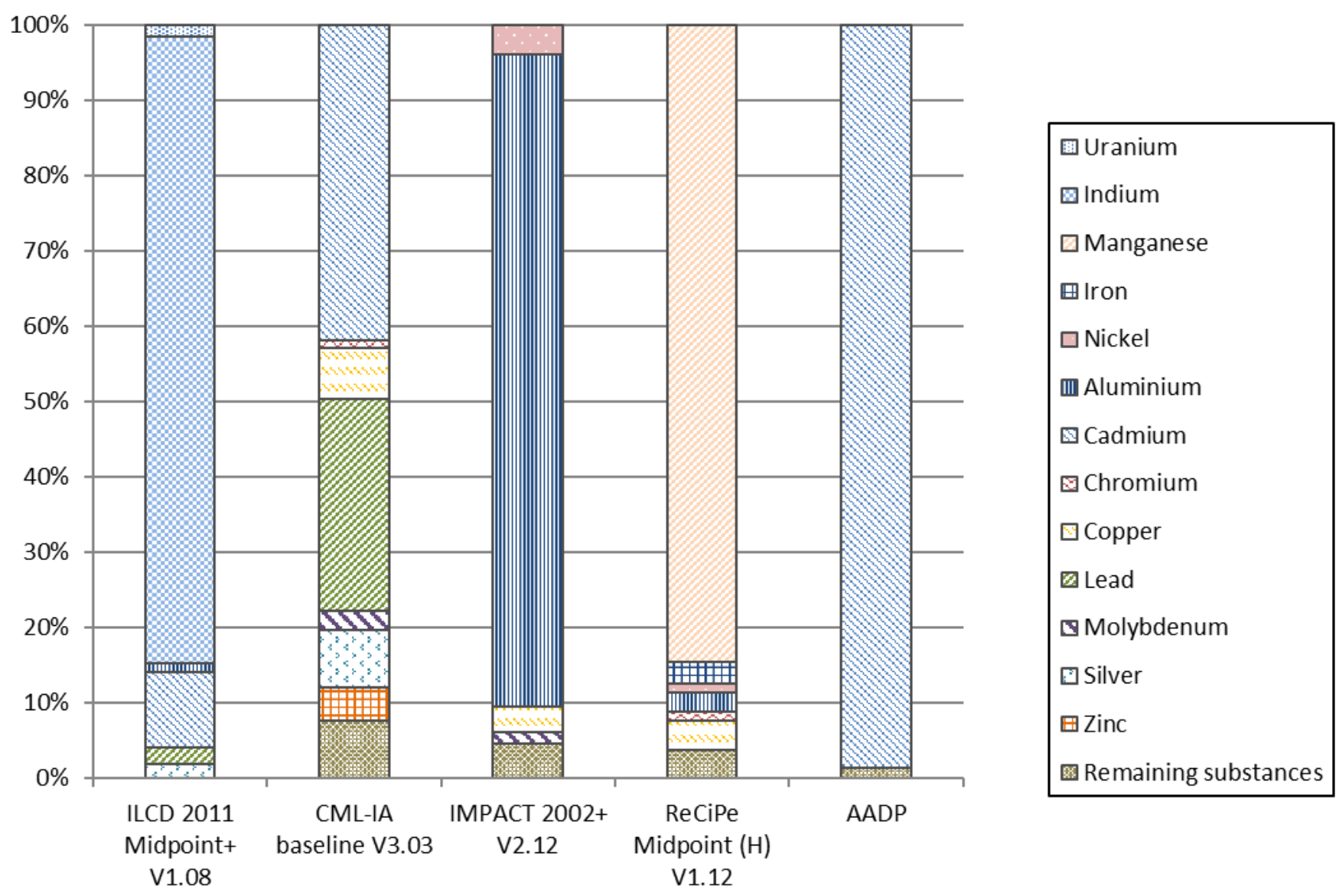

Figure 6 - Relative substance contribution to abiotic depletion considering 5 different impact assessment methods (Scenario S1). 
P. M. Stotz, M. Niero, N. Bey, and D. Paraskevas Resour. Conserv. Recycl., vol. 127, no. December, pp. 96-106, 2017 http://dx.doi.org/10.1016/j.resconrec.2017.07.013

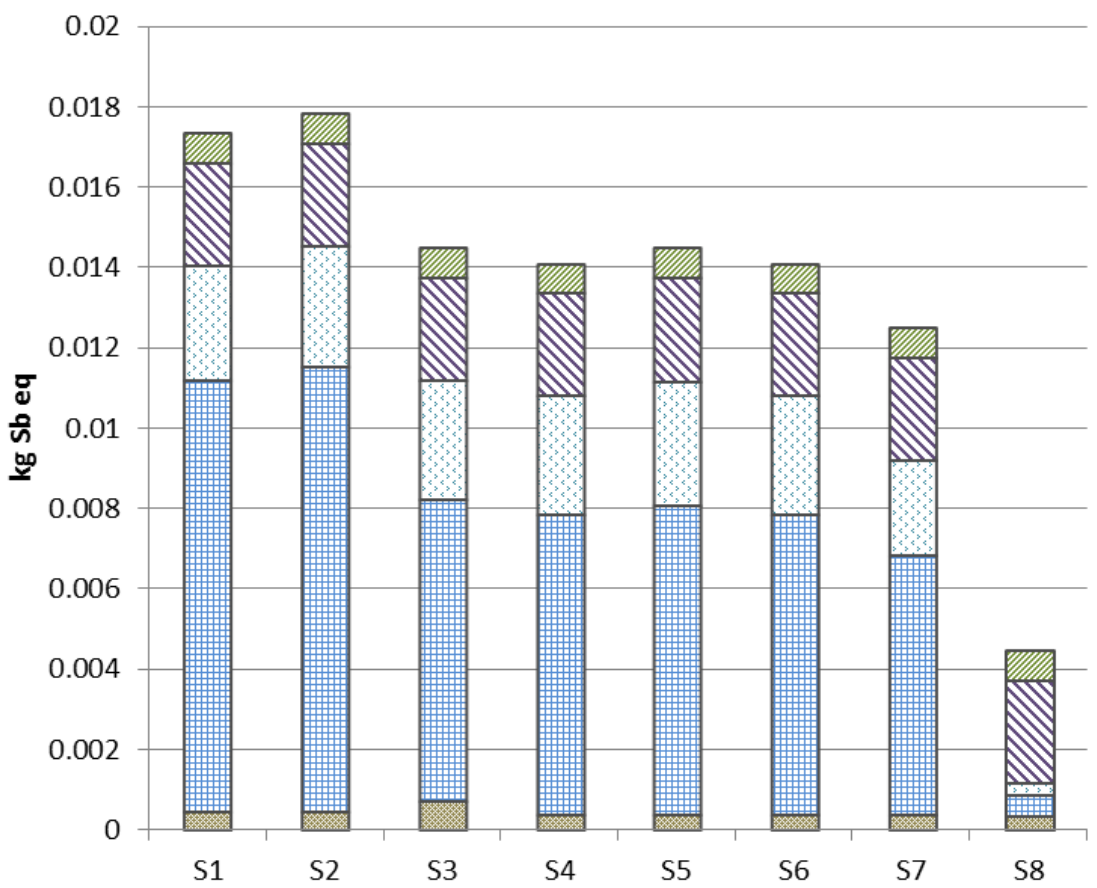

四 Sheet rolling, aluminium processing $\Delta$ Electricity, high voltage $\{\mathrm{GB}\}$

GAluminium, primary production

田Zinc primary production

图 Remaining processes

Figure 7 - Abiotic resource depletion results of each scenario, including contribution of the most significant 
P. M. Stotz, M. Niero, N. Bey, and D. Paraskevas

Resour. Conserv. Recycl., vol. 127, no. December, pp. 96-106, 2017

http://dx.doi.org/10.1016/j.resconrec.2017.07.013

400

401

402

403

404

405

406

407

408

409

410

411

412

413

414

415

416

417

418

419

420

421

422

423

424

425

426

427

428

\subsection{Results of the sensitivity analyses}

\subsubsection{Transport intensity and electricity consumption}

Additional scenarios with variations in transport and electricity parameters were modelled. The sensitivity

analyses indicated a higher susceptibility to changes in energy consumption rather than transport intensity. In terms of the latter, only a sixteen-fold increase of the total transport distance (i.e. $16 \times 529 \mathrm{~km}$ ) led to a significant impact on the GWP impact category, indicating a low sensitivity to fluctuations in transport, which can be explained by the relative low weight of the $A B C$. This is consistent with the only marginal increase in transport intensity resulting from the slightly higher weight of the uni-alloy $A B C$.

The $10 \%$ reduction in electricity consumption during the production and the filling of the $A B C$ led to a $4.5 \%$ decrease in GWP. In the case of aluminium cans, where most of the environmental impacts come from raw material extraction and production, no significant differences in terms of potential environmental impacts were found when different $\%$ and sources of renewable energy are used in the manufacturing stage (Niero et al. 2017). Their research on $33 \mathrm{cl}$ aluminium cans produced in the UK market concluded that only by increasing the $\%$ of renewable energy in primary aluminium production, it is possible to significantly reduce the environmental impacts of aluminium cans.

\subsubsection{Effects of End-of-Life modelling approaches}

The comparison of the two EoL modelling approaches delivered consistent results for all scenarios (Figure

3). While the SEQ method gives full credit to the recyclability of the material and assumes a $100 \%$ virgin materials for the production, the ES method gives credits to both recycled content and recycling rate and includes burdens arising from the respective processes. In line with other studies (e.g. van der Harst et al., 2016), the ES provides higher impact score values as only 50\% of the benefits arising from recycling are attributed to this product life cycle. From Figure 3 it becomes obvious that the benefit originates from the decreased primary aluminium production, while the rest of the processes remain similar. For S3 it can be clearly shown that energy intensive EoL procedures are working diametrical to the benefits gained from accounting $100 \%$ of the recycling rate to this lifecycle. Consequently the difference arising from the modelling is in S3 not as significant as in the remaining scenarios. S8 is the only scenario that performs better in the ES compared to its SEQ version. This is due to the allocation of the burdens arising from collection, sorting and re-melting, respectively the connected material losses, which are to $100 \%$ attributed to this life cycle with SEQ method. 
P. M. Stotz, M. Niero, N. Bey, and D. Paraskevas

Resour. Conserv. Recycl., vol. 127, no. December, pp. 96-106, 2017

http://dx.doi.org/10.1016/j.resconrec.2017.07.013

429

430

431

432

433

434

435

436

437

438

439

440

441

442

443

444

445

446

447

448

449

450

451

452

453

454

455

456

457

458

459

460

\section{Discussion}

\subsection{Validation of LCA results}

The scenario analysis confirmed the results of previous LCA studies that found the greatest environmental abatement potential for the $A B C$ system in the increased recycling rate, recycled content and by reducing the energy consumption of the ABC production (Niero et al., 2016, Amienyo and Azapagic, 2016, van der Harst et al., 2016).

The screening of novel technologies (i.e. LIBS \& SSR) did not result in significant environmental abatement potentials in terms of GWP. The results for AD however, indicate impact reductions, which range from trivial (4\%, Impact 2002+) to significant (48\%, Recipe). Besides the introduction of the uni-alloy can in the current UK market (S2), all scenarios highlight the importance to retain the materials quality by separating the waste streams. However, this study falls short of recommending how this separation may be achieved, as the LIBS (S4) and the return system (S6) perform similar in all impact categories. The level of detail in this study is not sufficient to differentiate the two, even though one can expect significant differences in terms of transport intensity, material losses and changes in infrastructure, which are not accounted for here.

The results of the SSR route (S3) are consistent with the findings of Duflou et al. (2015), which reflect the higher energy consumption of the diffusion bonding process compared to the re-melting route. As opposed to their study, the here performed assessment does not give any credit for the fact that the SSR route directly results in a near net shape, compared to the re-melting route which requires an additional hotextrusion step to get to a similar output. However, the future development of the SSR technology will have to show, to which degree it is able to substitute the traditional re-melting route and consequently decrease material losses to a minimum.

The results of the alternate material composition, as assessed with the scenarios including the uni-alloy can (S2, S3 and S5), do not indicate any environmental benefits. Buffington and Peterson (2013) attest the unialloy potential to increase the materials reuse, but point out that the recycling rate has to reach a high level in order to generate the supply necessary for a high recycling content. In the current system, the UBC is remolten and the melt diluted with primary aluminium and alloying elements to subsequently be reprocessed into body coils (Løvik and Mueller, 2014). Considering the cumulative material losses and the continuous growth of the industry, it is argued here, opposed to Buffington and Peterson (2013), that it is unlikely that the current $A B C$ design will hinder a full reintegration of UBCs in subsequent life cycles.

Both, S7 and S8 highlight the importance to re-integrate the UBC in the production of new $A B C s$, since there is a clear reduction of impact across all impact categories. Yet, technological innovation alone will not be able to increase the efficiency of the materials' circularity. While technological innovations (assessed in 
S3, S4, S5) certainly have the ability to increase the quality of the scrap stream and reduce materials losses, other factors determine the full exploitability of the ABC life cycle (derived from UNEP, 2013). First, the recycling rates depend on customer behaviour, embedded in a 'recycling culture'. Second, infrastructure needs to be in place to enable the consumer to recycle UBC in a waste stream that retains its quality. Third, increasing the recycled content depends on the availability of a high quality scrap feedstock in order to avoid downcycling and an industry that promotes the use of aluminium with a high recycled content.

The sensitivity analysis confirmed that the modelling approach does influence the LCA results (van der Harst et al. 2016). For the goal of this study the ES approach, as included in the PEF guide, was the correct choice, as it allows to alternate recycled content and recycling rate simultaneously. This approach distributes the environmental impacts of virgin production, recycling processes and disposal amongst the different products of the cascade system. The EoL formula included in the PEF guide is aligned with three key criteria: physical realism (i.e. conformity with the as-is situation), distribution of burdens and benefits in a product cascade system and applicability (Allacker et al., 2017). A formula taking into account the number of recycling cycles of a material would be preferred to reach physical realism and to allocate burdens and benefits of repeatedly recycling of a material over the different products in a product cascade system. However, data on the number of recycling cycles is currently not available for all products on the market and hence fails the criterion of applicability (Allacker et al., 2017). Therefore, such an approach is suited to model material circularity in case of a single life cycle, as in the current study, but also in case of multiple loops (Niero and Olsen, 2016).

A major challenge in the interpretation of results of $A D$ is the dominance of specific elements in the results of the different LCIA results, such as cadmium and lead (CML baseline), indium (CML non-baseline), manganese (Recipe), aluminium (Impact 2002+) and cadmium (AADP). While manganese and aluminium are an integral part of the alloy, cadmium, lead and indium are not. The three elements occur as byproducts of a zinc mine and are therefore modelled as such in the underlying ecoinvent dataset, which was used in this study. However, the economic allocation applied in the ecoinvent dataset does, to date, not include resource correction (ecoinvent support, 2017). The lacking transparency of the assumptions behind the available datasets is therefore a key aspect that needs to be improved in order to be able to provide reliable results, as also pointed out by other authors (van Genderen et al., 2016; Brogaard et al., 2014).

\subsection{Assessment of material circularity}

Considering the lacking consensus regarding AD characterisation, complementary methods to LCA might be considered for the interpretation of results instead. Rigamonti et al. (2016) tested the influence of the selection of the LCIA method for the resource depletion impact category in the case of recovery of electric 
P. M. Stotz, M. Niero, N. Bey, and D. Paraskevas

Resour. Conserv. Recycl., vol. 127, no. December, pp. 96-106, 2017

http://dx.doi.org/10.1016/j.resconrec.2017.07.013

493

494

495

496

497

498

499

500

501

502

503

504

505

506

507

508

509

510

511

512

513

514

515

516

517

518

519

520

521

522

523

524

525

and electronic waste. A sensitivity analysis has been performed, adopting different sets of characterization factors based on existing models for minerals and metals as well as recently proposed sets accounting for critical raw materials and the results showed misalignment in terms of contribution analysis at the substance level among the different methods. When confronted with the choice of impact assessment methods for $A D$, the practitioner is well advised to choose more than one method to ensure consistency of the observed trends. Further, it is advisable to simply compare scenarios that concern the same product on the basis of their total score in AD. Otherwise the huge discrepancy in characterisation factors might lead to misleading results and make a proper interpretation difficult. In cases where the primary production of resources is energy intensive (such as aluminium), GWP can be used as an approximation to model material circularity, as it clearly shows the benefit of avoided production. However, as shown in the results above, materials with a low mass fraction and energy consumption during production might get underestimated (e.g. manganese, silicon).

LCA is regularly applied with complementary methods to assess material circularity. Niero et al (2017) defined a framework combining LCA and the Cradle to $\mathrm{Cradle}^{\circledR}(\mathrm{C} 2 \mathrm{C})$ certification program to identify which actions should be prioritized to achieve a continuous material loop for beverage packaging, both from an environmental and an economic point of view. Recent studies combined LCA with Material Flow Analysis (MFA) (Turner et al., 2016; Sevigné-Itoiz et al., 2014) or the Cumulative Exergy Extraction from the Natural Environment (CEENE) method (Huysman et al., 2017; Van Eygen et al., 2016), each describing an integrated assessment for specific waste stream scenarios. Turner et al. (2016) applied LCA and MFA in order to support local solid waste management decision making by assessing the performance of different waste policy measures in terms of archived recycling rates and greenhouse gas reduction. Sevigné-Itoiz et al. (2014) used the same MFA methodology to map global streams of aluminium scrap and applied LCA to assess consequences of changes in the system. Both studies conclude independently that the combination of MFA and LCA is a 'prerequisite to consistent development from a linear towards a circular economy' (Sevigné-Itoiz et al., 2014, p. 94). Huysman et al. (2017) propose for this purpose a circular economy performance indicator (CPI) based on the CEENE method to expresses the quality of recycled material to its virgin counterpart. Van Eygen et al. (2016) analyse the efficiency of recycling streams by a MFA and subsequently apply CEENE to express resource consumption of the recycling scheme.

Material circularity has also been discussed as a key prerequisite in the context of circular economy. The Material Circularity Indicator (MCI), developed by the Ellen MacArthur Foundation and Granta (2015), allows measuring how well a product performs in the context of a circular economy. The inputs used to calculate the $\mathrm{MCl}$ refer to the following four aspects: i) material input in the production process, i.e. the recycled content; ii) utility during use stage, i.e. how long and intensely the product is used; iii) destination 
P. M. Stotz, M. Niero, N. Bey, and D. Paraskevas Resour. Conserv. Recycl., vol. 127, no. December, pp. 96-106, 2017 http://dx.doi.org/10.1016/j.resconrec.2017.07.013

526 after use, i.e. the recycling rate and iv) efficiency of recycling, i.e. the yield of the recycling process.

527 However, as the present case study demonstrates, such information is not sufficient to identify the best

528 option to close material loops. The inclusion of an assessment of the potential environmental impacts in 529 terms of climate change proved sufficient to perform a screening assessment.

530 The number of different approaches suggested to assess material circularity, respectively their variations, 531 highlights the fact that it is hardly sufficient to consider only a single parameter, but a holistic approach is 532 required, which considers the implications of market forces and policy development on a given scenario.

533 The here discussed screening was able to shed some light on novel technologies that might boost materials' 534 circularity from an environmental perspective, but the results will have to be assessed from an economic 535 and social perspective as well, in order to assure a solution with minimal trade-offs. 
P. M. Stotz, M. Niero, N. Bey, and D. Paraskevas

Resour. Conserv. Recycl., vol. 127, no. December, pp. 96-106, 2017

http://dx.doi.org/10.1016/j.resconrec.2017.07.013

\section{Conclusion}

537 In order to assess whether novel technologies have the potential to increase material circularity, we performed a screening LCA under the inclusion of most recent methodological developments. The results demonstrate the importance of novel technologies to improve the waste stream's quality/purity and a consequently reduced impact on AD. However, the results show a high sensitivity regarding the choice of impact assessment method for abiotic depletion. The most significant changes showed to be based on the increase of recycled content and recycling rate, emphasising the need to expand the scenario analysis to economic and social aspects in order to capture and understand the implications of a systemic change, i.e. the implications and consequences of changes in e.g. consumer behaviour, infrastructural conditions, and legal instruments.

Besides $A D$, all other impact categories show only insignificant differences for the scenarios in which recycling rate and recycled content are constant (S1 -S6). This indicates that the environmental influence related to the included alloying elements is similar and hence results in negligible differences, making it impossible to recommend either of the technological novelties. This is contrasted by the fact that a large scale implementation has effects on factors such as transport intensity and energy consumption in the recycling process, which have not been accounted for and may lead to significant different environmental 552 impacts not captured by this study.

553 In general, the results confirm the hotspots found in the current life cycle of the $A B C$. While strategies exist 554 to reduce the pressure on resource consumption and to increase the retention of material quality, no 555 evidence for such actions targeting the production has been identified (beyond conventional resourceefficiency related improvements). With $46 \%$ of GWP at current conditions, the production is the second largest contributor to life cycle GWP of ABCs after the primary aluminium production. As recycling rates continuously increase, production may soon replace materials extraction and production as the major contributor to the $A B C^{\prime}$ 's environmental profile.

We reflected on the methodological choices within LCA and discussed various approaches and indicators proposed in recent studies that illustrate the trend towards combined methods to holistically assess the circularity of materials. These combined methods are especially valuable when considering that the effort to reach consensus on how to characterize abiotic resource depletion (AD) has only just started (Drielsma, 2016b). Such a further development in impact assessment methodology would increase LCA's capabilities to not only assess scenarios based on their quantity (e.g. material mass recovered), but would allow of sustainable strategies for the management of specific waste streams. 
P. M. Stotz, M. Niero, N. Bey, and D. Paraskevas Resour. Conserv. Recycl., vol. 127, no. December, pp. 96-106, 2017 http://dx.doi.org/10.1016/j.resconrec.2017.07.013

\section{Acknowledgements}

569 CLAP (Closed Loop Aluminium Packaging) project awarded by Climate KIC (APSP0026_2016-1.3.1-

570 373_P240-60)

571 Monia Niero deeply acknowledges the Carlsberg Foundation for funding the project "Absolute Circular

572 Economy" (ACE) toolkit to support companies in the implementation of Circular Economy strategies from an 573 Absolute environmental sustainability perspective".

574 
P. M. Stotz, M. Niero, N. Bey, and D. Paraskevas

Resour. Conserv. Recycl., vol. 127, no. December, pp. 96-106, 2017

http://dx.doi.org/10.1016/j.resconrec.2017.07.013

\section{References}

ALFED, 2017. UK Aluminium Industry Fact Sheet 5 - Aluminium Recycling. http://www.alfed.org.uk/files/Fact\%20sheets/5-aluminium-recycling.pdf.(Accessed on 14. January 2017).

Allacker, K., F. Mathieux, S. Manfredi, N. Pelletier, C. De Camillis, F. Ardente, and R. Pant. 2014. Allocation solutions for secondary material production and end of life recovery: Proposals for product policy initiatives. Resources, Conservation and Recycling 88: 1-12

Allacker, K., Mathieux F., Pennington D., Pant R., 2017. The Search for an Appropriate End-of-Life Formula for the Purpose of the European Commission Environmental Footprint Initiative. Int. J. Life Cycle Assess. doi:10.1007/s11367-016-1244-0.

Amienyo, D., Azapagic, A., 2016. Life cycle environmental impacts and costs of beer production and consumption in the UK. Int. J. Life Cycle Assess. 21 (4), pp 492-509.

Bauxite Index, 2017. Alumina Production and Trade: Outlook. https://thebauxiteindex.com/en/cbix/industry101/alumina-101/production-trade/outlook\#alumina 101. (Accessed on 10. January 2017).

Bellqvist, D., Ångström, S., Magnusson, M., Nordhag, L., Falk, O., Gustavsson, L., 2015. Closing the loop - Processing of waste by-product from aluminum recycling into useful product for the steel industry. Chem. Eng. Trans., 45(October 2015), pp.661-666.

BCME, 2016. The Can Makers UK Market Report 2015. Beverage Can Makers Europe EEIG. http://www.canmakers.co.uk/wp-content/uploads/2016/05/Market-report-2015.pdf. (Accessed on 19. January 2017)

Behrens, B.-A., Bouguecha, A., Brunotte, K., Dannenberg, M., Huskic, A., Bonhage, M., 2016. Reprocessing of aluminum chips by hot backward extrusion. Prod. Eng., pp.1-8.

Brogaard, L. K., Damgaard A., Jensen M. B., Barlaz, M., Christensen T. H., 2014. "Evaluation of Life Cycle Inventory Data for Recycling Systems." Resour. Conserv. Recycl. 87: 30-45. doi:10.1016/j.resconrec.2014.03.011.

Buffington, J., Peterson R., 2013. "Defining a Closed-Loop U.S. Aluminum Can Supply Chain Through Technical Design and Supply Chain Innovation." JOM 65 (8): 941-50. doi:10.1007/s11837-013-0615-2.

Dansk retursystem, 2016. About the Danish Return System - Management Report. http://www.danskretursystem.dk/wp-content/uploads/2016/11/UK august 2016.pdf.

Defra, 2016. UK statistics on waste - 2010 to 2014. UK Department for Environment and Rural affairs.

Din EN 573-3, 2003-2010: Aluminium und Aluminiumlegierungen- Chemische Zusammensetzung und Form von Halbzeug-Teil 3: Chemische Zusammensetzung und Erzeugnisformen; Deutsche Fassung EN 573-3. 28

Drielsma, J. A., Russell-Vaccari, A. J., Drnek, T., Brady, T., Weihed, P., Mistry, M., Simbor, L. P., 2016a. Mineral resources in life cycle impact assessment - defining the path forward. Int. J. Life Cycle Assess, 21(1), pp.85-105.

Drielsma, Johannes, Ruth Allington, Thomas Brady, Jeroen Guinée, Jane Hammarstrom, Torsten Hummen, Andrea Russell-Vaccari, Laura Schneider, Guido Sonnemann, and Pär Weihed. 2016b. "Abiotic Raw-Materials in Life Cycle Impact Assessments: An Emerging Consensus across Disciplines." Resources 5 (1): 1-10. doi:10.3390/resources5010012.

Duflou J.R., Tekkaya E.A, Haase M., Welo T., Vanmeensel K., Kellens K.., Dewulf W., Paraskevas D., 2015. Environmental assessment of solid state recycling routes for aluminium alloys: Can solid state processes significantly reduce the environmental impact of aluminium recycling? CIRP Annals - Manufacturing Technology, 64, 37-40

EAA, 2013. "Recycled content" vs "End-of-life recycling rate". European Aluminium Association, Brussels, Belgium.

EAA, 2017a. Aluminium in Use. http://www.european-aluminium.eu/about-aluminium/aluminium-in-use/. (Accessed on 14. January 2017)

EAA, 2017b. Aluminium used in packaging. http://european-aluminium.eu/about-aluminium/aluminium-inuse/packaging/ (Accessed on 22. January 2017)

EC, 2013. Commission Recommendation of 9 April 2013 on the use of common methods to measure and communicate the life cycle environmental performance of products and organisations. European Commission, Brussels.

EC-JRC-IES, 2011. International Reference Life Cycle Data System (ILCD) Handbook-Recommendations for Life Cycle Impact Assessment in the European Context. First edit. Publications Office of the European Union, Luxemburg. EUR 24571 EN.

EC-JRC-IES, 2012. Characterisation factors of the ILCD Recommended Life Cycle Impact Assessment methods. Database and Supporting Information. First edition. February 2012. EUR 25167. Luxembourg. Publications Office of the European Union; 2012. 
P. M. Stotz, M. Niero, N. Bey, and D. Paraskevas

Resour. Conserv. Recycl., vol. 127, no. December, pp. 96-106, 2017 http://dx.doi.org/10.1016/j.resconrec.2017.07.013

629

Ellen MacArthur Foundation, 2013. Towards the Circular Economy Vol. 2: opportunities for the consumer goods sector. Ellen MacArthur Foundation. pp. 1-44.

Ellen Mac Arthur Foundation and Granta, 2015. Circularity Indicators. An approach to measuring circularity; Methodology. Ellen MacArthur Foundation and Granta Design. pp. 1-98.

EN 13920: Aluminium and Aluminium Alloys-Scrap” ,European Committee for Standardization, 2003

Gaustad, G., Olivetti, E. \& Kirchain, R., 2012. Improving aluminum recycling: A survey of sorting and impurity removal technologies. Resour. Conserv. Recycl., 58, pp.79-87. Available at: http://linkinghub.elsevier.com/retrieve/pii/S0921344911002217.

Gesing, A. J., Subodh K. D., and Raouf O. L., 2015. Production of Magnesium and Aluminum-Magnesium Alloys from Recycled Secondary Aluminum Scrap Melts. JOM 68 (2). Minerals, Metals and Materials Society: 585-92. doi:10.1007/s11837-015-1720-1.

Goedkoop, M.; Spriensma, R., 2001. The Eco-Indicator 99: a Damage Oriented Method for Life Cycle Impact Assessment: Methodology Report, 3rd, ed; Publikatiereeks produktenbeleid; nr. 36A; Ministerievan Volkshiusvesting, Ruimtelijke Ordening en Milieubeheer: Den Haag, 2001.

Goedkoop, M., Heijungs, R., De Schryver, A., Struijs, J., van Zelm, R., 2013. ReCiPe 2008. A LCIA method which comprises harmonised category indicators at the midpoint and the endpoint level. Available at: http://www.presustainability.com/download/misc/ReCiPe main report final 27-02-2009 web.pdf.

Goedkoop, M., Oele, M., Leijting, J., Ponsioen, T., Meijer, E., 2016. Introduction to LCA with SimaPro. PRé. Available at: https://www.pre-sustainability.com/download/SimaPro8IntroductionToLCA.pdf

Guinée, J.B., Gorée, M., Heijungs, R., Huppes, G., Kleijn, R., de Koning, A., van Oers, L., Wegener Sleeswijk, A., Suh, S., de Haes, U., et al., 2002. Handbook on Life Cycle Assessment: Operational Guide to the ISO Standards; Kluwer Academic Publisher: Dordrecht, The Netherlands, 2002. Available Online: https://www.universiteitleiden.nl/en/science/environmental-sciences/tools-and-data\#CMLCA.

Hagelüken, C., 2007. The challenge of open cycles - Barriers to a closed loop economy demonstrated for consumer electronics and cars. R'07 World Congress - Recovery of Materials and Energy for Resource Efficiency, pp.1-11.

Hauschild, M. Z., Goedkoop', M., Guinée J., Heijungs, R., Huijbregts, M., Jolliet, O., Margni, M., 2013. Identifying Best Existing Practice for Characterization Modeling in Life Cycle Impact Assessment. Int. J. Life Cycle Assess. 18 (3): 683-97. doi:10.1007/s11367-012-0489-5.

Hegazy, H., Abdel-Wahab, E. A., Abdel-Rahim, F. M., Allam, S. H., Nossair, A. M. A., 2013. Laser-Induced Breakdown Spectroscopy: Technique, New Features, and Detection Limits of Trace Elements in Al Base Alloy. Appl. Phys. B 115 (2): 173-83. doi:10.1007/s00340-013-5589-9.

Humbert, S., Rossi, V., Margni, M., Jolliet, O., Loerincik, Y., 2009. Life cycle assessment of two baby food packaging alternatives: Glass jars vs. plastic pots. Int. J. Life Cycle Assess. 14(2): 95-106.

Huysman, S., De Schaepmeester, J., Ragaert, K., Dewulf, J., De Meester, S., 2017. Performance Indicators for a Circular Economy: A Case Study on Post-Industrial Plastic Waste. Resour. Conserv. Recycl. 120. Elsevier B.V.: 46-54. doi:10.1016/j.resconrec.2017.01.013.

Ingason, H.T., Sigfusson, T.I., 2014. Processing of Aluminum Dross: The Birth of a Closed Industrial Process. JOM, 66(11), pp.2235-2242.

ISO, 2006a. Environmental Management. Life Cycle assessment. Principle and Framework. ISO 14040:2006. Geneva, Switzerland.

ISO, 2006b. Environmental Management. Life Cycle Assessment. Requirements and Guidelines. ISO 14044:2006. Geneva, Switzerland.

Jolliet, O., Margni, M., Charles, R., Humbert, S., Payet, J., Rebitzer, G., Rosenbaum R., 2003. IMPACT 2002+: A New Life Cycle Impact Assessment Methodology. Int. J. Life Cycle Assess. 8 (6), 324-330.

Laurent, A., Olsen, S.I., Hauschild, M.Z., 2010. Carbon footprint as environmental performance indicator for the manufacturing industry. CIRP Ann.-Manuf. Technol. 59 (January (1)), 37-40, CIRP. Available from: http://linkinghub. elsevier.com/retrieve/pii/S0007850610000090.

Løvik, A., Mueller, D.B., 2014. A material flow model for impurity accumulation in beverage can recycling systems. Light Met. 90, 7-11.

Modaresi, R. \& Müller, D.B., 2012. The role of automobiles for the future of aluminum recycling. Environ. Sci. Technol., 46(16), pp.8587-94.

Nakajima, K., Takeda, O., Miki, T., Matsubae, K., Nagasata, T., 2011. Thermodynamic analysis for the controllability of elements in the recycling process of metals. Environ. Sci. Technol. 45, 4929e4936.

Nakajima, K., Takeda, O., Miki, T., Matsubae, K., Nakamura, S., Nagasaka, T., 2012. Thermodynamic analysis of contamination by alloying elements in aluminium recycling. Environ. Sci. Technol. 44, 5594e5600. 
P. M. Stotz, M. Niero, N. Bey, and D. Paraskevas

Resour. Conserv. Recycl., vol. 127, no. December, pp. 96-106, 2017

http://dx.doi.org/10.1016/j.resconrec.2017.07.013

684

685

686

687

688

689

690

691

692

693

694

695

696

697

698

699

700

701

702

703

704

705

706

707

708

709

710

711

712

713

714

715

716

717

718

719

720

721

722

723

724

725

726

727

728

729

730

731

732

733

734

735

736

737

Niero, M., Negrelli, A. J., Hoffmeyer, S. B., Olsen, S. I., Birkved, M., 2016. Closing the loop for aluminum cans: Life Cycle Assessment of progression in Cradle-to-Cradle certification levels. J. Clean. Prod., 126, pp.352-362.

Niero, M., Olsen, S.I., 2016. Circular economy : to be or not to be in a closed product loop ? A Life Cycle Assessment of aluminium cans with inclusion of alloying elements. Resour. Conserv. Recycl., 114, pp.18-31. Available at: http://dx.doi.org/10.1016/i.resconrec.2016.06.023

Niero, M., Hauschild M.Z., Hoffmeyer S.B., Olsen S.I., 2017. Combining Eco-Efficiency and Eco-Effectiveness for Continuous Loop Beverage Packaging Systems. Lessons from the Carlsberg Circular Community. J. Ind. Ecol. DOI: 10.1111/jiec.12554 (in press)

Nogueira, C. A., Trancoso, M. A., Pedrosa, F., Crujeira, A. T., Oliveira, P. C., Gonçalves, A. M., Margarido, F., Novais Santos, R., Durão, F., Guimarães, C., 2015. "The Role of Automated Sorting in the Recovery of Aluminium Alloys Waste." In Wastes: Solutions, Treatments and Opportunities - Selected Papers from the 3rd Edition of the International Conference on Wastes: Solutions, Treatments and Opportunities, 2015, 177-82. CRC Press/Balkema.

Novelis, 2012. Sustainability Report 2012. Available at: http://novelis.com/sustainability/downloads/. Novelis Inc.

Oers, L. van, Koning, A., de \& Guinée, J.B. \& Huppes, G., 2002. Abiotic resource depletion in LCA: improving characterisation factors for abiotic depletion as recommended in the new Dutch LCA Handbook. Delft: Ministry of Transport, Public Works and Water Management.

Oers, L. van \& Guinée, J., 2016. The Abiotic Depletion Potential: Background, Updates, and Future. Resources, 5(1), p.16. Available at: http://www.mdpi.com/2079-9276/5/1/16/htm.

Paraskevas D., Kellens K., Renaldi, Dewulf W., Duflou J.R. 2013. Closed and Open Loop Recycling of Aluminium: A Life Cycle Assessment perspective. 11th Global Conference on Sustainable Manufacturing: Innovative Solutions, Berlin, Germany, 305-310

Paraskevas, D., Vanmeensel, K., Vleugels, J., Dewulf, W., Deng, Y., Duflou, J.R., 2014. Spark Plasma Sintering As a SolidState Recycling Technique: The Case of Aluminum Alloy Scrap Consolidation. Materials 7, 5664-5687

Paraskevas D., Kellens K., Dewulf W., Duflou J.R., 2015a. Environmental modelling of aluminium recycling: a Life Cycle Assessment tool for sustainable metal management. Journal of Cleaner Production, 105, 357-370. Available from: http://linkinghub.elsevier.com/retrieve/pii/S0959652614010646.

Paraskevas D., Kellens, K., Van de Voorde, A., Dewulf, W., Duflou, J.R., 2015b Environmental impact analysis of primary aluminium production at country level. Procedia CIRP 26, 455-460.

Paraskevas, D., Dadbakhsh, S., Vleugels, J., Vanmeensel, K., Dewulf, W., Duflou, J.R., 2016. Recycling of pure Mg and AZ31 Mg machining chips via spark plasma sintering. Materials \& Design 109, 520-529.

Rigamonti, L., Falbo, A., Zampori, L., Sala, S., 2016. Supporting a Transition towards Sustainable Circular Economy: Sensitivity Analysis for the Interpretation of LCA for the Recovery of Electric and Electronic Waste. Int. J. Life Cycle Assess. doi:10.1007/s11367-016-1231-5.

Rosenbaum, R. K., Bachmann, T. M., Gold, L. S., Huijbregts, M. A. J., Jolliet, O., Juraske, R., Köhler, A., Larsen, H. F., MacLeod, M., Margni, M., McKone, T. E., Payet, J., Schuhmacher, M., van de Meent, D., Hauschild, M.Z., 2008. USEtox - the UNEP-SETAC toxicity model: recommended characterization factors for human toxicity and freshwater ecotoxicity in life cycle impact assessment. Int. J. Life Cycle Assess. 13(7):532-546

Santero, N. \& Hendry, J., 2016. Harmonization of LCA methodologies for the metal and mining industry. Int. J. Life Cycle Assess, 21(11), pp.1543-1553. Available at: http://dx.doi.org/10.1007/s11367-015-1022-4.

Saleh, Y., 2016. Comparative life cycle assessment of beverages packages in Palestine. J. Clean. Prod., 131, pp.28-42.

Schneider, L., Berger, M., Finkbeiner, M., 2015. Abiotic Resource Depletion in LCA - Background and Update of the Anthropogenic Stock Extended Abiotic Depletion Potential (AADP) Model. Int. J. Life Cycle Assess 20 (5): $709-21$. doi:10.1007/s11367-015-0864-0.

Sevigné-Itoiz, E., Gasol, C. M., Rieradevall, J., Gabarrell, X., 2014. Environmental Consequences of Recycling Aluminum Old Scrap in a Global Market. Resour. Conserv. Recycl. 89 (August). Elsevier: 94-103. doi:10.1016/j.resconrec.2014.05.002.

Seyring, N., Dollhofer, M., Weissenbacher, J., Bakas, I., McKinnon, D., 2016. Assessment of collection schemes for packaging and other recyclable waste in European Union-28 Member States and capital cities. Waste Manag. Res., 34(9), pp.947-956. Available at: http://wmr.sagepub.com/cgi/doi/10.1177/0734242X16650516.

Simon, B., Ben Amor, M., Földényi, R., 2015. Life cycle impact assessment of beverage packaging systems: focus on the collection of post-consumer bottles. J. Clean. Prod. 112, 238e248.

Shamsudin, S., Lajis, M. \& Zhong, Z.W., 2016. Evolutionary in Solid State Recycling Techniques of Aluminium: A review. Procedia CIRP, 40, pp.256-261. 
P. M. Stotz, M. Niero, N. Bey, and D. Paraskevas

Resour. Conserv. Recycl., vol. 127, no. December, pp. 96-106, 2017

http://dx.doi.org/10.1016/j.resconrec.2017.07.013

Stanford, K., 2016. Recycling aluminium packaging - A UK Case Study. Aluminium Insider, 04 October 2016. Available at: http://aluminiuminsider.com/recycling-aluminium-packaging-a-uk-case-study/. (Accessed January 7th, 2017).

Steinert, 2016. Press release - New sorting technology for the separation into different aluminium alloys http://www.steinertglobal.com/grp/en/news/details/new-sorting-technology-for-the-separation-into-differentaluminium-alloys/. (Accessed on 17. January 2017).

Stern, M., 1945. U.S. Patent 2,391,752

Stichling, J. \& Nguyen-Ngoc, D., 2009. Life Cycle Inventory and Impact Analysis for Beverage Cans. Final Report. PE International.

Takezawa, T., Uemoto, M. \& Itoh, K., 2014. Combination of X-ray transmission and eddy-current testing for the closedloop recycling of aluminum alloys. J. Mater. Cycles Waste Manag., 17(1), pp.84-90.

Turner, D. A., Williams, I. D., Kemp, S., 2016. Combined Material Flow Analysis and Life Cycle Assessment as a Support Tool for Solid Waste Management Decision Making. J. Clean. Prod.129. Elsevier Ltd: 234-48. doi:10.1016/j.jclepro.2016.04.077.

UNEP, 2011. Recycling Rates of Metals - A status report, A report of the Working Group on the Global Metal Flows to the International Resource Panel, Graedel, T.E., Alwood, J., Birat, J.-P., Reck, B.K., Sibley, S.F., Sonnemann, G., Buchert, M., Hagelüken, C.. Available from: http://www.unep.org/resourcepanel/Portals/24102/PDFs/Metals Recycling Rates 110412-1.pdf. (Accessed January 7th, 2017).

UNEP, 2013. Metal Recycling: Opportunities, Limits, Infrastructure, A Report of the Working Group on the Global Metal Flows to the International Resource Panel. Reuter, M. A.; Hudson, C.; van Schaik, A.; Heiskanen, K.; Meskers, C.; Hagelüken, C. Available from: http://www.unep.org/resourcepanel/portals/24102/pdfs/metal_recycling full_report.pdf (accessed January 14th, 2017).

Van Genderen, E., Wildnauer, M., Santero, N., Sidi, N., 2016. A global life cycle assessment for primary zinc production. Int. J. Life Cycle Assess., 21(11), pp.1580-1593. Available at: http://dx.doi.org/10.1007/s11367-016-1131-8.

Van der Harst, E., Potting, J. \& Kroeze, C., 2016. Comparison of different methods to include recycling in LCAs of aluminium cans and disposable polystyrene cups. Waste Manag. (New York, N.Y.), 48, pp.565-83.

Van Eygen, E., De Meester, S., Tran, H. P. Dewulf, J., 2016. Resource Savings by Urban Mining: The Case of Desktop and Laptop Computers in Belgium. Resour. Conserv. Recycl.107 (February). Elsevier: 53-64. doi:10.1016/j.resconrec.2015.10.032.

Wernet, G., Bauer, C., Steubing, B., Reinhard, J., Moreno-Ruiz, E., Weidema, B., 2016. The ecoinvent database version 3 (part I): overview and methodology. Int. J. Life Cycle Assess., [online] 21(9), pp.1218-1230. Available at: http://link.springer.com/10.1007/s11367-016-1087-8 (accessed December 14th, 2016). 